\title{
Bypass ilio-hepático para revascularización de isquemia mesentérica crónica
}

\section{Revascularization of chronic mesenteric ischemia with common iliac to hepatic artery bypass}

June Blanco Larizgoitia, Melina Vega de Céniga, Andoni González Fernández, Luis Estallo Laliena

Servicio de Angiología y Cirugía Vascular. Hospital Galdakao-Usansolo. Galdakao, Vizcaya

\section{INTRODUCCIÓN}

La isquemia mesentérica crónica se define como la insuficiencia arterial para satisfacer las necesidades del tracto gastrointestinal de $>3$ meses de duración (1). La incidencia se estima en $<1 / 100000$ habitantes, de los que un 70\% son mujeres. En los pacientes con patología arterial periférica la incidencia aumenta, y se observa oclusión o estenosis significativa en al menos 1 vaso en el 25-29\% de los casos, y en $>1$ vaso en el 15\%. La clínica es a menudo inespecífica, por lo que suele demorarse el diagnóstico hasta 1-2 años. La tríada más característica y habitual es: dolor abdominal pospandrial, sitofobia y diarrea, lo que conlleva una pérdida de peso. El diagnóstico se realiza principalmente mediante angio-TAC.

\section{CASO CLÍNICO}

Presentamos el caso de una mujer de 74 años que ingresó por dolor abdominal inespecífico y generalizado con pérdida de peso progresiva de > 1 año de evolución, con diarreas asociadas en los últimos meses. Como antecedentes presentaba hipertensión arterial, hiperuricemia y mielofibrosis, así como varias cirugías digestivas: colecistectomía laparoscópica y resección de íleon terminal y ciego por endometriosis. La paciente negaba tabaquismo previo. En la exploración física destacaban un índice de masa corporal de $17,5 \mathrm{~kg} / \mathrm{m}^{2}$ y un soplo periumbilical.

En el angio-TAC se observaban: oclusión completa del tronco celíaco (TC) con permeabilidad de las arterias hepática común y esplénica por colateralidad, oclusión completa de la arteria mesentérica superior (AMS), con revascularización distal gracias a la arcada de Riolano, y estenosis severa del ostium de la arteria mesentérica inferior (AMI). Estos hallazgos fueron confirmados con una angio-RMN (Fig. 1). Se realizó una revascularización endovascular mediante angioplastia transluminal percutánea de la AMI con balones de $4 \times 20$ y $5 \times 20 \mathrm{~mm}$, con lo que se consiguió un excelente resultado angiográfico, por lo que se decidió no añadir un stent. No se intentó revascularizar la AMS, ya que presentaba una oclusión proximal extensa de $6 \mathrm{~cm}$ de longitud difícil de recanalizar. La paciente presentó buena evolución, con dolores abdominales residuales leves y ocasionales y aumento de $2 \mathrm{~kg}$ de peso en los meses siguientes.

Catorce meses después, la paciente refería nuevamente ángor mesentérico. En un nuevo angio-TAC se confirmó la reestenosis crítica de la AMI. Se intentó de nuevo realizar una revascularización endovascular de este vaso en dos ocasiones, sin éxito, por lo que
Recibido: 04/03/2019 • Aceptado: 8/03/2019

Blanco Larizgoitia J, Vega de Céniga M, González Fernández A, Estallo Laliena L. Bypass ilio-hepático para revascularización de isquemia mesentérica crónica. Angiología 2019;71(2):74-76.

DOI: http://dx.doi.org/10.20960/angiologia.00013
Correspondencia:

June Blanco Larizgoitia. Servicio de Angiología y Cirugía Vascular. Hospital Universitario de Galdakao. Labeaga Auzoa. 48960 Galdakao, Vizcaya.

e-mail: juneblanc092@gmail.com 


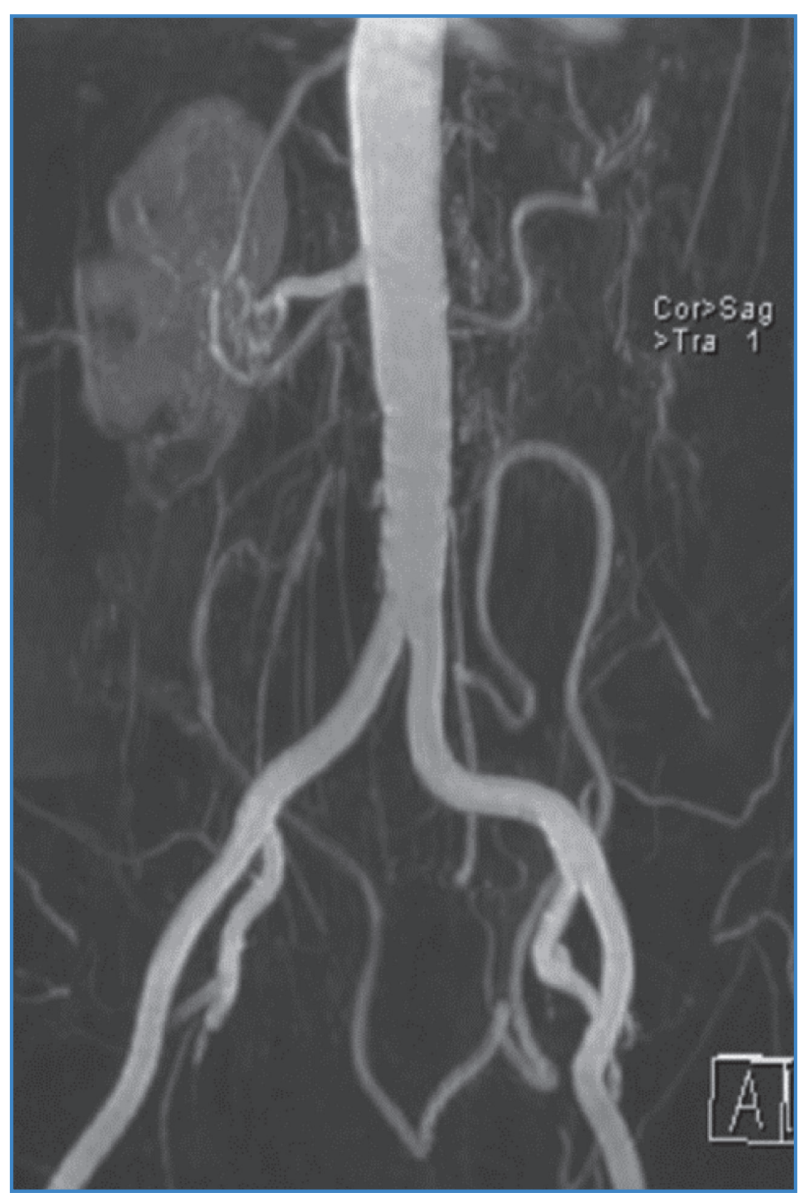

Figura 1. aRMN en el que se observan: el tronco celíaco ocluido, la arteria mesentérica superior ocluida con recuperación de flujo en región distal desde la arcada de Riolano.

se decidió mantener tratamiento conservador con dieta fraccionada y doble antiagregación (ácido acetilsalicílico y clopidogrel). La paciente continuó muy sintomática, incluso con dolor abdominal en reposo, por lo que finalmente se decidió realizar una revascularización abierta. Mediante laparotomía transversa, y con un equipo bidisciplinar (cirugía vascular y general), se realizó un bypass iliohepático con prótesis de PTFE de $6 \mathrm{~mm}$ anillada desde la arteria ilíaca común izquierda (AICI) hasta la arteria hepática, tunelizando el injerto de forma retropancreática (Fig. 2A). La aorta supraceliaca e infrarrenal presentaban calcificación severa y extensa, que comprometían el clampaje y la anastomosis, por lo que se optó por una revascularización extraanatómica desde la $\mathrm{AICl}$ como localización donante preferencial. La arteria hepática se encontraba sana y con calibre conservado, lo que la
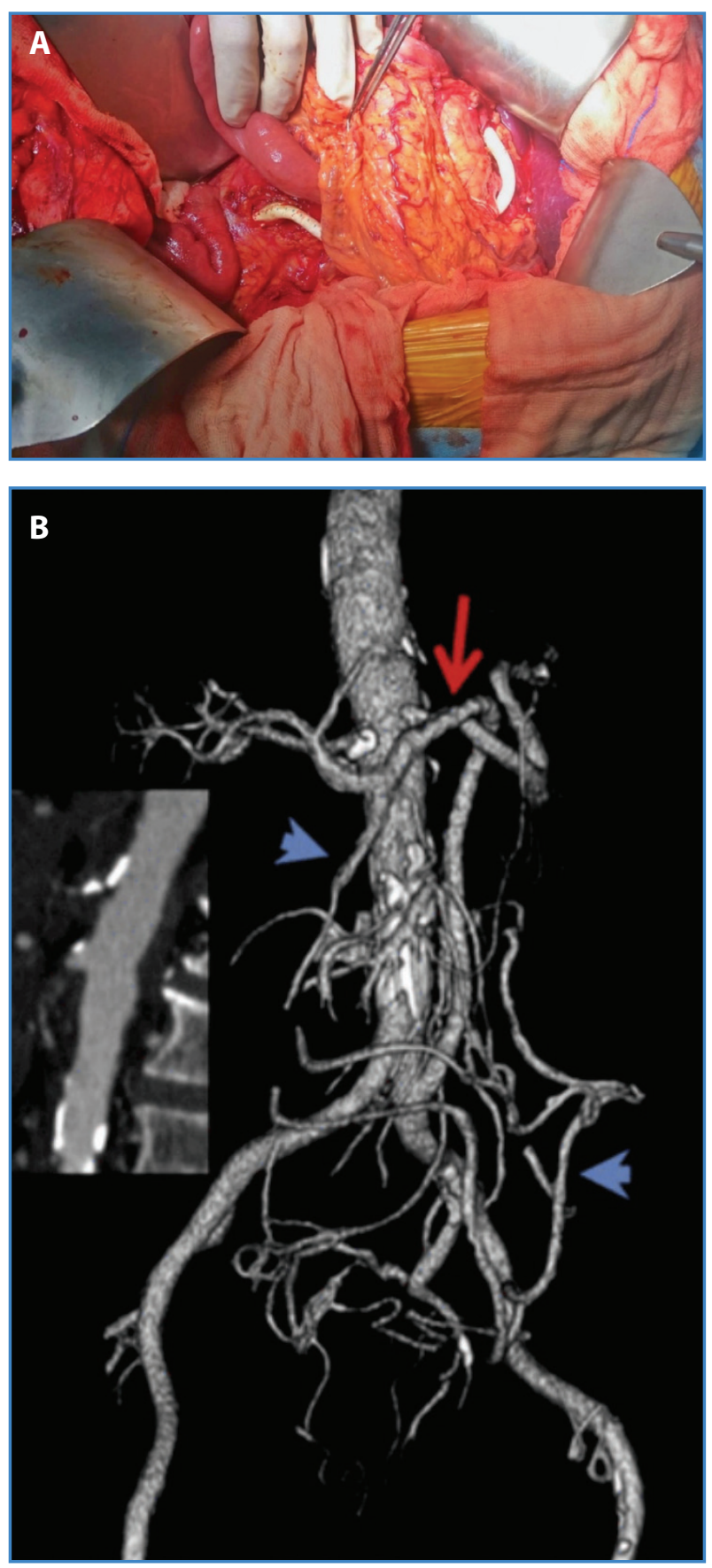

Figura 2. A. Bypass iliaca común izquierda-hepática común con prótesis de ePTFE de $6 \mathrm{~mm}$ anillada. B. Angio-TAC de control realizado un mes tras la cirugía. La flecha roja señala el Bypass iliohepático permeable; las azules indican la circulación colateral peripancreática y la arcada de Riolano. (Imagen reproducida con permiso, publicada previamente en Eur J Vasc Endovasc Surg 2017;53(6):791. DOl: http://dx.doi. org/10.126/j.eus.2017.02.011).

convertía en un adecuado vaso receptor, puesto que tanto el TC como la AMS se encontraban ocluidos. Tras la cirugía se consiguió el cese completo del dolor 
abdominal y de la diarrea, con buena tolerancia a la dieta basal, ganando $3 \mathrm{~kg}$ de peso en 3 meses. En el angio-TAC de control un mes tras la cirugía, se objetivó el bypass permeable (Fig. 2B, flecha roja) y extensa circulación colateral peripancreática e intestinal (Fig. 2B, flechas azules).

Dieciséis meses después de la última revascularización, la paciente se sometió a un recambio electivo de cadera izquierda por coxartrosis y protrusión acetabular. Durante la intervención sufrió inestabilidad hemodinámica por sangrado y, en el posoperatorio inmediato, presentó dolor abdominal agudo y generalizado con hipotensión arterial, taquicardia y elevación de los parámetros analíticos infecciosos e inflamatorios. En un angio-TAC urgente se observaba isquemia difusa del intestino delgado y colon derecho con el bypass permeable. La sospecha clínica fue de trombosis aguda de vasos terminales y de circulación colateral del territorio esplácnico, a pesar de conservar el bypass permeable y funcionante. La paciente fue valorada por el Servicio de Cirugía General, que desestimó la resección intestinal por la extensión afectada. Se instauró tratamiento paliativo. La paciente falleció en pocas horas.

\section{DISCUSIÓN}

Existen opciones endovasculares y abiertas para intentar la revascularización de pacientes con isquemia mesentérica crónica sintomática. Las primeras son mínimamente invasivas, pero adolecen de elevadas tasas de reestenosis y recurrencia clínica. Las segundas, de entrada, son más agresivas, con un riesgo quirúrgico inasumible para muchos pacientes, pero ofrecen mejores resultados a largo plazo una vez superado el posoperatorio inmediato $(1,2)$. La elección de unas u otras dependerá de la situación del paciente, de sus características anatómicas y de la disponibilidad y experiencia del equipo. En cualquier caso, a pesar de una revascularización eficaz, estos pacientes son vulnerables a recurrentes episodios de isquemia por la naturaleza y la posible progresión de la enfermedad de base.

Como conclusión, la revascularización visceral abierta es una opción a considerar en pacientes con isquemia mesentérica crónica, especialmente cuando el tratamiento endovascular ha fallado o no está indicado. En ocasiones, las características anatómicas del paciente obligan a idear soluciones personalizadas atípicas.

\section{BIBLIOGRAFÍA}

1. Björck M, Koelemay M, Acosta S, et al. Management of diseases of mesenteric arteries and veins. Eur J Vasc Endovasc Surg 2017;53:460-510.

2. Cai W, Li X, Shu C, et al. Comparison of clinical outcomes of endovascular versus open revascularization for chronic mesenteric ischemia: A meta-analysis. Ann Vasc Surg 2015;29:934-40. 